\title{
Playlab: Telling Stories with Technology (Workshop Summary)
}

\author{
Julie Williamson \\ University of Glasgow \\ Glasgow, Scotland \\ Julie.Williamson@glasgow.ac.uk
}

\author{
Tom Flint \\ Edinburgh Napier University \\ Edinburgh, Scotland \\ t.flint@napier.ac.uk
}

\author{
Chris Speed \\ Edinburgh College of Art \\ Edinburgh Scotland \\ c.speed@ed.ac.uk
}

\begin{abstract}
This one-day workshop explores how playful interaction can be used to develop technologies for public spaces and create temporal experiences.
\end{abstract}

\section{CCS CONCEPTS}

- Human-centered computing $\rightarrow$ Field studies

- Human-centered computing $\rightarrow$ Activity centered design

- Human-centered computing $\rightarrow$ Ubiquitous and mobile computing design and evaluation methods

\section{KEYWORDS}

Playful interaction, storytelling, deployments.

ACM Reference format:

Julie R. Williamson, Tom Flint, and Chris Speed. 2017. Playlab: Telling Stories with Technology (Workshop Summary).

In Proceedings of 19th ACM International Conference on Multimodal Interaction (ICMI'17). ACM, New York, NY, USA, 2 pages. https://doi.org/10.1145/3136755.3137022

\section{ORGANISERS}

This workshop is organised by the current leaders of the Scottish Informatics and Computing Science Alliance (SICSA) PlayLab short research theme. SICSA short themes provide funding to explore new topics in computing science through workshops and events.

Permission to make digital or hard copies of part or all of this work for personal or classroom use is granted without fee provided that copies are not made or distributed for profit or commercial advantage and that copies bear this notice and the full citation on the first page. Copyrights for thirdparty components of this work must be honored. For all other uses, contact the Owner/Author.

ICMI '17, November 13-17, 2017, Glasgow, UK

(c) 2017 Copyright is held by the owner/author(s).

ACM ISBN 978-1-4503-5543-8/17/11.

https://doi.org/10.1145/3136755.3137022

\section{Julie R. Williamson, University of Glasgow}

Julie R. Williamson is a Lecturer in Human Computer Interaction (HCI) at the University of Glasgow. Her research focuses on designing and evaluating technologies for public spaces including novel display hardware, evaluations of user experience, and whole-body interactions. She has extensive experience completing evaluations of novel input and output techniques in real world settings.

\section{Tom Flint, Edinburgh Napier University}

Tom Flint is a lecturer in the School of Computing at Edinburgh Napier University. Tom is a practitioner with a history of exhibiting aesthetic interactive work. Tom's recently completed $\mathrm{PhD}$ examined the phenomenon of appropriation focusing on interactive art for enquiry. Tom's research, practice and teaching center around physical computing and creative technologies.

\section{Professor Chris Speed, Edinburgh College of Art}

Chris Speed is Chair of Design Informatics at the University of Edinburgh where his research focuses upon the Network Society, Digital Art and Technology, and The Internet of Things. Chris has sustained a critical enquiry into how network technology can engage with the fields of art, design and social experience through a variety of international digital art exhibitions, funded research projects, books journals and conferences

\section{INTRODUCTION TO PLAYLAB}

The goal of the PlayLab short theme is to bring together researchers and practitioners interested in playful interaction from a variety of disciplines. Often the focus of our work is on overcoming the constraints of specific technologies and learning their nuances and various uses. By concentrating on play and playfulness our events and workshops aim to create a collaborative and supportive environment where technology is a tool for creating fun, happiness and engagement.

Our workshops and events have explored a range of multimodal interaction techniques including multitouch surfaces (infrared visual and capacitive hardware), tangible interactive devices, whole body input using cameras, projected interfaces, $360^{\circ}$ 
content and virtual reality experiences. We are interested in how multimodal interaction can create playful public experiences, By bringing together researchers and practitioners in this area, we will be better placed to examine the role of technology in the everyday. We hope to engage with different critical viewpoints from a variety of backgrounds.

\section{PLAYLAB IN THE PAST}

Playlab has produced two events to date:

March 17th 2016 an evening panel with contributions from Robyn Taylor (Openlab Newcastle University) and artist Alan Brown.

November 30th 2016 Playlab Day \& Night. During the day, an interactive piece was created from scratch for exhibition that evening. In the evening, we presented the created work and hosted talks from Paul Maguire (Glasgow School of Art) and artists The Dennis and Debbie Club.

\section{PLAYLAB AT ICMI 2017}

\subsection{Motivation}

This workshop will examine the creation and production of a narrative told with and through interactive technology. Participants are expected to take an active part in creating an interactive piece that explores storytelling through a multimodal installation.

Our motivation is to explore and critique methods with which technology can be used as a medium for storytelling.

\subsection{Expected Outcomes}

This workshop will produce a functioning interactive artwork that is driven by narrative. The piece will be exhibited throughout the duration of the conference. We will work with the conference organisers to identify a suitable installation space and timelines.

There is also an opportunity for workshop participants to consider the nature of narrative for creative technology with the possibility of producing work for dissemination by publication.

\subsection{Impact}

This workshop will afford an opportunity for researchers interested in exploring creative uses of technology to collaborate and network. Previous Playlab sessions have led to collaborations and further explorations between participants.

\section{WORKSHOP FORMAT}

This full-day workshop will involve gathering a group of researchers and practitioners in a supportive and collaborative creative environment.

Tentative Program

The workshop will revolve around the development and production of an installation with the majority of the workshop time spent building a working prototype.

The workshop will also make use of the production space available in the School of Computing Science at the University of Glasgow, which Julie R. Williamson manages. This is located near to the workshop venue and will provide the necessary technical support for the workshop.

10:00 Welcome to workshop participants and overview of event

10:30 Storytelling concepts initial brainstorming session

11:30 Hardware/technical support overview

12:00 Concept refinement and plan complete

1:00 Lunch

2:00 Workshop build and prototype completion

5:30 Workshop wrap-up and deployment plan

Workshop Paper Submission and Review

This workshop will invite an optional two-page position paper, although we will allow any format of submissions, including the SIGCHI archival format, poster submission, or any multimedia submission. We hope this participation model will ensure a diverse group of participants, and allow people from a range of disciplines to submit meaningful work.

Workshop participants will be selected by the organisers based on these submissions in a curated review process.

Application is through the workshop website https://icmiplaylab.wixsite.com/playlabworkshop 